Miao, C., Qian, S., \& Humphrey, R. H. (accepted, September 7, 2018). Senior Leaders in

Small Enterprises: Insights into the Field of Entrepreneurship. Industrial and

Organizational Psychology.

\begin{abstract}
Senior leaders in many small enterprises cannot afford some of the leadership development practices advocated by Reynolds et al. (2018) in their focal article. For example, assessment centers run by outside professional consultants are likely to be too costly and time consuming. In addition, senior leaders in small enterprises need training in leadership skills specific to leaders of small enterprises. For example, because of their limited resources, they need training in the most effective bootstrapping practices. They also need training in how to develop and manage relationships with organizational outsiders, in particular financiers. These leaders may also need training in creativity and innovation, business ethics, and general leadership skills. A variety of low cost options may help leaders of small enterprises gain the skills they need.
\end{abstract}

Keywords: leadership; entrepreneurship; leader development 


\section{Senior Leaders in Small Enterprises: Insights into the Field of Entrepreneurship}

The focal article (Reynolds et al., 2018) reviewed and discussed the challenges, practices, and opportunities for the assessment and development for senior leaders. They summarized a set of accepted wisdom for assessing senior leaders in the areas of assessment criteria, contexts, and implementation, and meanwhile, pointed out what should be explored and done in the future. One of the central premises of the focal article seems to be built on the assumption that organizations may have sufficient resources to follow the accepted wisdom to ensure the quality and effectiveness of assessment and development for senior leaders. In addition, most, if not all, of the research findings summarized and discussed in the focal article may be based on the studies under the context of established companies. Hence, whether the implications and suggestions from the focal article can generalize to small enterprises remain an open question. For example, a typical small enterprise in the United States is a company capitalized with about $\$ 25,000$ (Shane, 2009). Most of these enterprises are highly centralized, have negative cash flow, and have troubles in securing cash and in obtaining customer acceptance (Rutherford \& Buller, 2007). Thus, these companies may not be able to follow the accepted wisdom as recommended in the article. We realize that some small businesses and start-ups are extremely well-funded, so our following comments apply only to those small enterprises with scarce resources.

As one example of the differences between senior leaders in established companies relative to small enterprises, hiring a professional firm to conduct an assessment center would lead to hefty costs to a company, which is not quite feasible for a small enterprise. A leader in a small enterprise would more likely consider avoiding prohibitive expenses by exploring options related to people who are willing to work on pro bono basis (e.g., partnering with a local entrepreneurship clinic) or as interns (e.g., students). However, even this approach may not be 
sufficient because running an assessment center is quite time-consuming and labor intensiveand, running a low quality center jeopardizes the validity and utility of an assessment center. Overall, it is highly unlikely that a leader in a small enterprise would be able to enlist an experienced assessment center professional willing to conduct it without any remuneration.

The assessment center example is simply one, of many, ways in which senior leaders in small enterprises face a different set of issues relative to senior leaders from established companies. As another example, Reynolds et al. (2018) discussed the importance of assessing and developing teamwork among leaders (i.e., shared capacity of leadership or leadership team) and between a leader and other team members. Teamwork matters for large, established companies inasmuch as a corporate organization is prone to dysfunction if individuals in the company stop effectively working with each other, thus breeding a toxic climate that is detrimental to firm performance. Teamwork still matters under the context of small enterprises; as an organization forms and develops over time, groups of individuals within the organization not just the founder(s) - can have a significant impact on an organization. In fact, teamwork may matter more under the context of small enterprises because small enterprises have fewer people, fewer resources, and untenable infrastructures (Rutherford \& Buller, 2007); thus, dysfunctional teamwork can quickly cause a small enterprise to malfunction or even melt down. Nevertheless, small enterprises face a different set of challenges concerning teamwork from large, established companies because small enterprises typically operate with a few people who are often family members and/or friends (Shane, 2009). The preexisting relationships that exist in small enterprises can influence the nature of teamwork, and such teamwork based on strong ties may restrict one's access to fresh, creative ideas and breed norms of reciprocity that oblige one to 
conform to others' ideas or opinions even if they are poor and/or faulty (Stam, Arzlanian, \& Elfring, 2014).

In a small enterprise, conflict is more likely to arise between the leaders (or founders) and other stakeholders such as a financier (Higashide \& Birley, 2002). When conflict does arise between a leader and team members in a small enterprise, it is not always undesirable — nuanced research findings show that there can be a positive relationship between task conflict and venture performance (de Jong, Song, \& Song, 2013), although relationship conflict is less desirable.

Entrepreneurial leaders from small enterprises are the key players in modern economy (Lazear, 2005)—roughly one-third of all new job creation in the United States, annually, between 1980 and 2010 was due to new and small firms (Decker, Haltiwanger, Jarmin, \& Miranda, 2014). Although they may have a smaller span of control than in larger firms, they are still senior leaders responsible for organizational strategy, organizational culture, and overall organizational policy. Accordingly, understanding senior leaders in small enterprises is of critical importance. And, it is clear that small enterprises are not simply miniature versions of their larger counterparts - rather, small enterprises face a distinct set of decisions and challenges that are unique to such enterprises (Rutherford \& Buller, 2007). Based on our literature review, we found several developmental practices that were not covered by the focal article and that need to be factored into the assessment and development of senior leaders in small enterprises. Metaanalytical studies have verified that entrepreneurship training programs are useful in improving performance outcomes (Martin, McNally, \& Kay, 2013), so the following developmental practices are likely to be both feasible and effective.

\section{Assessment and Development for Senior Leaders in Small Enterprises}

\section{Resource Acquisition}


Nearly $75 \%$ of small, emerging enterprises make little or no use of external debt or equity but instead utilize bootstrapping methods - highly creative approaches to obtain resources without raising money or equity from traditional sources - to survive in a competitive environment (Miao, Rutherford, \& Pollack, 2017). There are four prominent categories of bootstrapping practices (Jones \& Jayawarna, 2010; Miao et al., 2017): (a) customer-related bootstrapping (e.g., advance payments and expedited invoicing); (b) delay payment (e.g., negotiate payment conditions); (c) owner-related (e.g., use personal credit cards or resources from friends and family members); and (d) joint utilization (e.g., share equipment and/or employees with other firms). According to meta-analytic findings, bootstrapping practices vary in terms of the size of their impact on firm performance and some bootstrapping practices positively affect firm performance more than others (Miao et al., 2017). Due to the prevalence and importance of bootstrapping for small enterprises, senior leaders from small enterprises need to be able to employ effective bootstrapping practices to conserve the resources of their firms.

Although bootstrapping is an attractive option for senior leaders from small enterprises, one should not always choose bootstrapping in lieu of available external sources of debt or equity financing - external financing can be beneficial in terms of enhanced wealth and performance (Rutherford, Pollack, Mazzei, \& Sanchez-Ruiz, 2017) whereas different types of bootstrapping practices have either weak positive or no performance effect at all (Miao et al., 2017).

Overall, senior leaders from small enterprises have important choices to make here. Some leaders in small ventures may have a stronger inclination to bootstrap resources rather than engage in fundraising because they do not want to give up their control over their company or they are unable to secure funding due to the financiers' reluctance to grant money (Rutherford et 
al., 2017). Hence, senior leaders from small enterprises need to receive training and development in order to be educated about the importance of resource acquisition and to learn important skills related to resource conservation and deployment.

\section{Creativity/Ideation}

The failure rate for small enterprises is disappointingly high (Shane, 2009). One of the reasons for such a high failure rate is the tendency of small enterprises to not pursue an original idea, but simply develop a new venture based on a venture or idea that already exists-i.e., copycatting (Bhide, 1992). This lack of creativity in small enterprises is troubling, especially as meta-analytic findings show that creativity results in the generation of new and novel ideas that lead to innovation (Sarooghi, Libaers, \& Burkemper, 2015). And, we know that innovation positively influences firm performance for small- and medium-sized enterprises (Rosenbusch, Brinckmann, \& Bausch, 2011). To mitigate costly failures for small enterprises, senior leaders need to be fluent and capable in ideation and/or creativity skills because entrepreneurs who are creative and possess strong ideational skills are more successful than those who do not (Ames \& Runco, 2005).

\section{Business Ethics and Legitimacy}

Due to the high failure rates of small enterprises - and the pressure in such endeavors - it is documented that some individuals are willing to lie or misrepresent the facts in order to increase the propensity of success (Pollack \& Bosse, 2014; Rutherford, Buller, \& Stebbins, 2009). Leaders from small enterprises are likely to lie or engage in morally questionable behaviors because they are not viewed as tenable and permanent in the eyes of stakeholders; hence, they are constantly in high-stake environments where they must get necessary resources required for survival and/or growth (Pollack \& Bosse, 2014). Hence, they are motivated to 
manage stakeholders' impressions by presenting selected information and/or by using ambiguity to limit disclosing negative aspects of their businesses (Pollack \& Bosse, 2014). This is termed as a tendency to tell "legitimacy lies" (Rutherford et al., 2009). Put simply, small enterprises suffer from liabilities of newness and smallness and these liabilities make it less likely that the venture will have access to the information, resources, and customers needed to survive and grow (Morse, Fowler, \& Lawrence, 2007). Senior leaders from small enterprises may be highly motivated to seek strategies to reduce the impact of liability of smallness; one of these strategies is to tell legitimacy lies or deliberately misrepresent or withhold the facts and/or information concerning their company or themselves (Rutherford et al., 2009). The information asymmetry between small business leaders and stakeholders means that stakeholders are often unable to assess the legitimacy of small enterprises' claims, and this asymmetry creates the opportunity for small business leaders to lie stakeholders (Pollack \& Bosse, 2014). We recommend that senior leaders from small enterprises receive proper exposure to strategies that can reduce liabilities related to newness and smallness and thus avoid the need to lie.

\section{Costs for Assessment and Development of Senior Leaders in Small Enterprises}

The costs for developing the above-mentioned critical skills or knowledge may involve little or nearly no costs in some cases. For example, there are many entrepreneurship bootcamps, local entrepreneur meetings, university-sponsored workshops, and/or career assessment conferences that are available to senior leaders from small enterprises at minimal cost. Senior leaders from small enterprises may also subscribe to academic journals or practice-oriented readings or magazines to learn the latest knowledge about successful entrepreneurship approaches. There are also ample free online resources available to senior leaders from small enterprises regarding assessment and development that can be tailored to their unique context. In 
addition, small business leaders can join trade and professional associations and can benefit from the developmental opportunities provided by these associations.

Although the above low-cost solutions may generally be beneficial, they will be most beneficial if the bootcamps, meetings, etc., are targeted to small business owners, particularly ones with scarce resources. In addition, it must be admitted that these solutions may also expose small business leaders to unvetted practices. For example, small business leaders may be susceptible to unproven fads and trends espoused by mass media publications, but unproven by solid academic research and established human resources practices. Thus, small business leaders may benefit by hiring I/O psychologists as advisors and consultants. I/O psychologists with appropriate credentials can steer entrepreneurs with scarce resources towards programs and practices that are known to be effective and in keeping with professional standards. Although small business leaders may not be able to afford a well-staffed full-time HR department, they can still use I/O psychologists as occasional consultants to help keep them on the right path.

Perhaps most importantly, senior leaders in small enterprises need to have an active board of directors or advisors who they can turn to for leadership training advice, and who can mentor the small business leaders during the growth of the firm. I/O psychologists, because of their extensive connections with the business community, may help leaders of small enterprises find appropriate board members. When effectively managed, directors and advisors can play a vital role in helping new venture leaders craft an effective strategy (Garg \& Eisenhardt, 2017). Many entrepreneurs start a business when they have an idea for a new product, but once they began the new venture they find they are actively engaged in managing, leading, and supervising employees, and these activities require leadership skills, not just technical innovations. Formal training in leadership skills through university corporate education or regular university 
leadership courses may further enhance the senior leaders' chances of success, especially when the courses use leadership textbooks that feature entrepreneurial start-up cases as well as general leadership skills (e.g., Humphrey, 2013).

\section{References}

Ames, M., \& Runco, M. A. (2005). Predicting entrepreneurship from ideation and divergent thinking. Creativity and Innovation Management, 14, 311-315.

Baumol, W. J. (1996). Entrepreneurship: Productive, unproductive, and destructive. Journal of Business Venturing, 11, 3-22.

Bhide, A. (1992). Bootstrap finance: The art of start-ups. Harvard Business Review, 70, 109-117.

Decker, R., Haltiwanger, J., Jarmin, R., \& Miranda, J. (2014). The role of entrepreneurship in US job creation and economic dynamism. Journal of Economic Perspectives, 28, 3-24.

de Jong, A., Song, M., \& Song, L. Z. (2013). How lead founder personality affects new venture performance: The mediating role of team conflict. Journal of Management, 39, 18251854.

Garg, S., \& Eisenhardt, K. M. (2017). Unpacking the CEO-board relationship: How strategy making happens in entrepreneurial firms. Academy of Management Journal, 60, 18281858.

Higashide, H., \& Birley, S. (2002). The consequences of conflict between the venture capitalist and the entrepreneurial team in the United Kingdom from the perspective of the venture capitalist. Journal of Business Venturing, 17, 59-81.

Humphrey, R. H. (2013). Effective leadership: Theories, cases, and applications. Sage Publications. Los Angeles. ISBN: 978-1-4129-6355-8.

Jones, O., \& Jayawarna, D. (2010). Resourcing new businesses: social networks, bootstrapping and firm performance. Venture Capital, 12, 127-152.

Lazear, E. M. (2005). Entrepreneurship. Journal of Labor Economics, 23, 649-680. 
Martin, B. C., McNally, J. J., \& Kay, M. J. (2013). Examining the formation of human capital in entrepreneurship: A meta-analysis of entrepreneurship education outcomes. Journal of Business Venturing, 28, 211-224.

Miao, C., Rutherford, M. W., \& Pollack, J. M. (2017). An exploratory meta-analysis of the nomological network of bootstrapping in SMEs. Journal of Business Venturing Insights, $8,1-8$.

Morse, E. A., Fowler, S. W., \& Lawrence, T. B. (2007). The impact of virtual embeddedness on new venture survival: Overcoming the liabilities of newness. Entrepreneurship Theory and Practice, 31, 139-159.

Pollack, J. M., \& Bosse, D. A. (2014). When do investors forgive entrepreneurs for lying? Journal of Business Venturing, 29, 741-754.

Reynolds, D. H., McCauley, C. D., Tsacoumis, S., \& the Jeanneret Symposium Participants. (2018). A critical evaluation of the state of assessment and development for senior leaders. Industrial and Organizational Psychology: Perspectives on Science and Practice.

Rosenbusch, N., Brinckmann, J., \& Bausch, A. (2011). Is innovation always beneficial? A metaanalysis of the relationship between innovation and performance in SMEs. Journal of Business Venturing, 26, 441-457.

Rutherford, M. W., \& Buller, P. F. (2007). Searching for the legitimacy threshold. Journal of Management Inquiry, 16, 78-92.

Rutherford, M. W., Buller, P. F., \& Stebbins, J. M. (2009). Ethical considerations of the legitimacy lie. Entrepreneurship Theory and Practice, 33, 949-964.

Rutherford, M. W., Pollack, J. M., Mazzei, M. J., \& Sanchez-Ruiz, P. (2017). Bootstrapping: Reviewing the literature, clarifying the construct, and charting a new path forward. Group \& Organization Management, 42, 657-706.

Sarooghi, H., Libaers, D., \& Burkemper, A. (2015). Examining the relationship between creativity and innovation: A meta-analysis of organizational, cultural, and environmental factors. Journal of Business Venturing, 30, 714-731. 
Shane, S. A. (2008). The illusions of entrepreneurship: The costly myths that entrepreneurs, investors, and policy makers live by. Yale University Press.

Shane, S. (2009). Why encouraging more people to become entrepreneurs is bad public policy. Small Business Economics, 33, 141-149.

Stam, W., Arzlanian, S., \& Elfring, T. (2014). Social capital of entrepreneurs and small firm performance: A meta-analysis of contextual and methodological moderators. Journal of Business Venturing, 29, 152-173. 